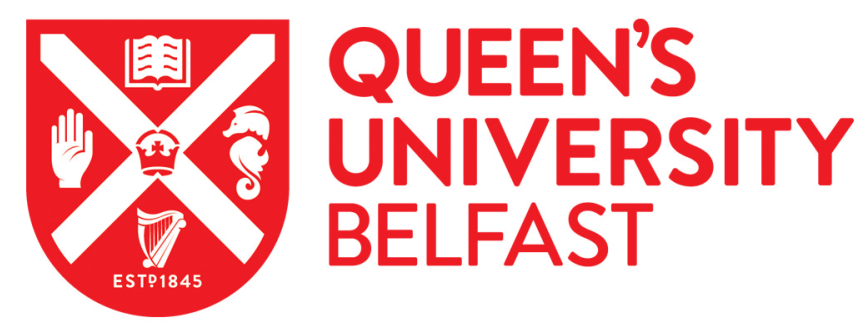

\title{
"There was no real importance put on them". Experiences of multiparous women and Pelvic Floor Muscle Exercise (PFME) prescription. A Qualitative Study
}

Reynolds, N., \& Wilson, I. M. (2019). “There was no real importance put on them”. Experiences of multiparous women and Pelvic Floor Muscle Exercise (PFME) prescription. A Qualitative Study. Physiotherapy Practice and Research, 40(2), 135-143. https://doi.org/10.3233/PPR-190135

Published in:

Physiotherapy Practice and Research

Document Version:

Peer reviewed version

Queen's University Belfast - Research Portal:

Link to publication record in Queen's University Belfast Research Portal

Publisher rights

Copyright 2019, IOS Press.

This work is made available online in accordance with the publisher's policies. Please refer to any applicable terms of use of the publisher.

\section{General rights}

Copyright for the publications made accessible via the Queen's University Belfast Research Portal is retained by the author(s) and / or other copyright owners and it is a condition of accessing these publications that users recognise and abide by the legal requirements associated with these rights.

Take down policy

The Research Portal is Queen's institutional repository that provides access to Queen's research output. Every effort has been made to ensure that content in the Research Portal does not infringe any person's rights, or applicable UK laws. If you discover content in the

Research Portal that you believe breaches copyright or violates any law, please contact openaccess@qub.ac.uk. 
"There was no real importance put on them". Experiences of multiparous women and Pelvic Floor Muscle Exercise (PFME) prescription. A Qualitative Study

Nuala Reynolds, Physiotherapy Department, Midlands Regional Hospital, Mullingar, Co Westmeath, Ireland.

Dr Iseult M Wilson*, Senior Lecturer, School of Nursing and Midwifery, Queen's University, Belfast.

*Corresponding author: Dr Iseult M Wilson, Senior Lecturer, School of Nursing and Midwifery, Queen's University Belfast, 97 Lisburn Road, Belfast, BT9 7BL 


\section{Abstract}

\section{Background}

Pregnancy is the main risk factor for the development of Stress Urinary Incontinence (SUI) which is known to have detrimental effects on quality of life in approximately $54.3 \%$ of women. The recommended treatment for SUI is to increase pelvic floor muscle strength, however, it is not clear why long-term adherence to pelvic floor muscle exercise (PFME) is poor.

\section{Objectives}

To understand multiparous women's experience of incontinence and the prescription of pelvic floor muscle exercise (PFME) in the ante and post-natal period on their first pregnancy, and the differences, if any, that they experienced on subsequent pregnancies.

\section{Methods}

Purposive sampling was used to recruit women who had two or more children. The 1:1 semistructured interviews were recorded, transcribed verbatim and anonymised. Thematic analysis was undertaken by both researchers, independently, and the codes and themes were agreed by consensus.

\section{Results}

Women were not aware that PFME could prevent incontinence, and the education provided was not sufficient to enable adherence to a PFME program. PFME were prescribed by health professionals, but there was a lack of detail, and the importance of PFME was not emphasised on first or subsequent pregnancies. On subsequent pregnancies, women were more aware of PFME and incontinence, however, this education came from informal sources, not the health care professionals providing the ante or post-natal care.

\section{Conclusions}


Health care professionals should include more information, and better guidance regarding PFMEs. Most of the information about PFMEs came from informal sources, especially on the second and subsequent pregnancies.

Word count 247

Key Words: Pelvic floor muscle exercises, urinary incontinence, ante-natal education, post-natal education, multiparous women 


\section{"There was no real importance put on them". Experiences of multiparous women and Pelvic Floor Muscle Exercise (PFME) prescription. A Qualitative Study}

\section{Introduction}

Pregnancy and Urinary Incontinence

Pregnancy is the main risk factor for the development of Stress Urinary Incontinence (SUI) which is known to have detrimental effects on quality of life in approximately $54.3 \%$ of women $[1,2]$. SUI is described by the International Continence Society as "urine loss whilst engaging in some form of physical effort such as jumping, coughing or sneezing" [3]. Studies have shown that SUI affects approximately half of the incontinent women $[4,5]$, therefore, SUI is an undeniable social problem. It can create embarrassment and negative self-perception and has been linked with impaired sexual relationships and reduced quality of life (QoL) [2,6]. Mascarenhas et al [7] reported that pregnant women with UI have statistically lower QoL scores than those without $\mathrm{UI}$, and QoL also worsens with gestational age [7].

Findings in several studies demonstrate that there is an increased risk of SUI with increased parity [2, 8-16] and a recent meta-analysis found that having a parity of 2 or more increased the risk of UI, with each additional birth increasing the ORs for any UI by $12 \%$ and in addition, that the risk of SUI specifically, was increased after the first birth [16].

\section{Ante-natal care in Ireland}

In Ireland, women without complications routinely receive ante-natal care from healthcare professionals, primarily midwives and GPs (General Practitioners) in the Health Service Executive (HSE). In addition to this care, which monitors the health and well-being of the mother and her baby, there are ante-natal classes offered by the healthcare provider. These classes aim to prepare the women for labour and parenthood, are primarily attended by women who are pregnant with their first baby, and are generally midwifery led with physiotherapy involvement. 
Pelvic Floor Muscle Exercise (PFME) for Incontinence in pregnancy and post-partum

The recommended treatment for SUI, according to the First International Consultation on Incontinence in 1998, is to increase PFM strength [17]. Muscles have considerable ability to selfrepair [18], and with appropriate management, such as Pelvic Floor Muscle Exercise (PFME), rehabilitation can occur and the PFM contraction can become stronger. The premise of this intervention is that a strong PFM contraction will improve urethral closure and pelvic organ support, thus protecting against SUI.

PFME is the first treatment of choice for pre and post-partum UI according to the French College of Gynaecologists and Obstetricians [19]. Wilson et al [20] showed that daily antenatal PFME could reduce the risk of post-partum UI by 50\%, and Sampselle et al [21] have shown similar results. Nulliparous women were able to avoid UI in pregnancy by performing PFME [22], and post-partum PFME has also shown to be effective in reducing UI 1 year after delivery [23]. A recent Cochrane systematic review concluded that post-natal women with persistent UI 3 months after delivery, and who received PFME training, were less likely to report UI at 12 months after delivery compared to women who did not receive treatment [24].

Despite this growing evidence for the effectiveness of PFME, incontinence post- partum still remains an issue for many women. Although improvements have been maintained until one year [19], longer term research does not provide such promising results. Glazener et al [25] followed up their participants at 6 and 12 years and found no significant improvement in incontinence between them and the control group. Viktrup and Lose [26] found similarly poor results with $42 \%$ of women, whose symptoms had resolved at 3 months post-partum, then subsequently had a reoccurrence of symptoms 5 years later. Also, of all the women who still had incontinence at 3 months following delivery, $92 \%$ still had symptoms 5 years later. More recently, Boyle et al [24] concluded in a systematic review, that although there was a paucity of long term studies, there was little evidence to suggest that the effect of PFME persisted in the 
long term (after 12 months). This review went onto suggest important implications for further research which recommended that future researchers must consider women who went on to have further children

\section{PFME education and adherence}

Several studies to date have been quantitative and investigate nulliparous women $[23,26-30]$. Mason et al [31,32] completed qualitative studies investigating how pelvic floor exercises were taught and women's reluctance to seek help for SUI following child birth. The studies revealed that there were shortfalls in the way PFME was being taught and that this led to issues around a lack of adherence. The lack of education as to where and how to seek treatment also prevented women from seeking help.

The reasons for poor adherence and higher rates of incontinence in multiparous women are still under-investigated. Despite PFME being so effective in treating ante and post-natal SUI, nonadherence is still an issue. $19 \%$ of women were found to be non-compliant with a 12 week ante natal PFME programme [27] and 11\% dropped out of an 8 week PFME class as it required too much effort and time [33]. Long term adherence was also poor in a 15 year follow up [34].

\section{Rationale}

The risk of SUI increases with increased parity, and although there is a consensus that PFME can reduce $\mathrm{UI}$, there are issue around education and non-adherence in women post-partum. In Ireland, women attend ante-natal classes during their first pregnancy, and PFMEs can be taught at this time. What is not known, is whether women routinely receive advice and education about PFMEs on their second and subsequent pregnancies. Whilst there is qualitative literature relating to women's experiences of having UI [11,35 - 38] and women's beliefs around causes of UI $[11,39]$ we are not aware of any studies investigating women's perceptions of PFMEs and 
more specifically, what multiparous women feel about their experience of PFME prescription in the ante and post-natal period.

This study therefore aimed to:

- Understand multiparous women's experience of PFME prescription by healthcare professionals (midwives and physiotherapists)

This was achieved by carrying out 1:1 interviews to meet the following objectives:

- To understand women's experience of PFME prescription by healthcare professionals:

- in the ante and post-natal period on their first pregnancy

- in the ante and post-natal period on their second and subsequent pregnancies

- To understand the differences, if any, that they experienced in relation to PFME prescription by healthcare professionals when comparing their first pregnancy with subsequent pregnancies

\section{Methods}

\section{Recruitment and data collection}

Ethical approval was granted by the Ulster University Ethics Committee (Project No: REC/15/0043). A purposive sampling technique was used because it was necessary to select participants who were able to present the requisite data [40]. In Ireland, routine ante- and post-natal care is provided by the HSE, which is a public service. Physiotherapists can work within the HSE (public health) or in a private clinic, and these clinics do not provide this routine ante-natal care.

The sample included: patients who had attended, or who were currently attending either the researcher (NR) or a colleague for treatment of UI post-partum, in their private clinic; participants who heard about the study from these patients (snow-ball effect); and participants who responded to posters in the local GP's (General Practitioner) surgery. Each woman that expressed an interest in 
taking part in the study, was given an information sheet, the opportunity to ask questions, and a cool-off period prior to agreeing to participate. Women were included if they had more than one child, with the youngest being at least six months old, and they had UI that started during pregnancy or following child birth. All participants gave written consent to audio recording of the interview. Exclusion criteria related to those who did not have sufficient English to complete the interview, who were unable to sit for the duration of the interview due to a medical condition, who were less than 6 months post-partum, or had UI before their first pregnancy. This was to ensure time for healing of the pelvic floor after childbirth, and that only women whose incontinence started after $2^{\text {nd }}$ or subsequent children were included. All interviews were conducted by the same researcher (NR) in a private space either within a physiotherapy clinic or the interviewee's own home. Interviews lasted up to 45 minutes and were audio recorded.

A qualitative design using 1:1 semi-structured interviews was adopted as it allowed the researcher to ask open-ended questions to encourage the participants to talk freely about their experiences [41]. A topic guide, which consisted of 4 pre-set questions, was developed by the two researchers in order to extract information to meet the aims of the study, and was iteratively developed by both researchers after each interview. Data collection continued until data saturation was reached. Each participant confirmed the content of the descriptive summary that was given to them following the interview.

\section{Reflexivity}

The researchers abided by the principles of reflexivity. The researcher (NR) was not involved with the routine ante- or post-natal care of any of the women. This care was delivered by the HSE, so the experiences of the women did not relate to care provided by the researcher. Both researchers were physiotherapists, and acknowledged their assumptions that it was likely that patients' experiences were different when they compared PFME prescription exercise following their first child, with that following their second and subsequent children. The main researcher who also carried out the 
interviews (NR) knew the women personally, and it was therefore impossible to conceal her profession, role etc. Measures were put in place to avoid any possibility of coercion, and participants were recruited with the help of an independent colleague, who then took no further part in the research. Following verification, the anonymised transcripts were independently analysed by both NR, and a different researcher (IW) who did not know any of the participants.

\section{Data Analysis}

All interview data were manually transcribed and anonymised (NR). Independent thematic analysis of the transcripts was completed by both researchers, and consensus reached. The transcripts were coded using an ontological perspective, and an In Vivo coding strategy [42] and the codes were then categorised into themes. There were several iterations of these categories and themes, and both researchers agreed on the over-arching theme and the supporting themes. Data saturation was reached following six interviews, as no new themes were emerging. An audit trail was created throughout both the data collection and analysis process.

\section{Results}

Six interviews were conducted with women ranging from aged $32-45$ years. Four of the women had 2 children, one had 3 children and one had 5 children. The over-arching theme was Lack of Understanding, and this was supported by a sub-theme of Education.

[Insert Figure 1 here]

Lack of Understanding

It was apparent from all six interviews that the women did not have a clear understanding of either urinary incontinence or the role of PFME in relation to managing the condition.

Most of the participants thought that urinary incontinence after child birth was normal, and related to having children: "you've had kids and that just happens, you know that's what I thought" (P5). 
They also felt that other women, and society in general, felt that UI was normal and "if you have babies at all, that you will leak, and this is a normal part of having children" (P6).

All six women admitted that they never understood the relationship between PFME and UI. They did not recall the word "incontinence" being mentioned in any of their ante or post-natal care on either their first or subsequent pregnancies. Although all women remember hearing about "pelvic floor exercises", none of them recall being told the reason for PFMEs, or about incontinence.

"not incontinence, no. I knew about pelvic floor exercises and it was important to do them straight afterwards, that was it. [pause] I still didn't understand why I was even having to do them". (P5)

Two women recall hearing the word "leakage", one from her GP at a post-natal appointment after her second child, and one from a public health nurse after her first child. They did not recall, however, a link between reducing or preventing leaking and PFMEs, nor the importance of PFMEs. "the public health nurse might have said something to me..... have you any leakage or anything?.......I was more concerned about speaking to her about the baby and feeding and me......it wasn't part of the conversation" $(P 1)$

\section{Education}

The over-arching theme, Lack of Understanding, included one sub-theme, Education, within which were two clear themes:: formal and informal.

Formal education

Formal education was that given by healthcare professionals at some stage during, or immediately after the pregnancy. All six women attended ante-natal classes during their first pregnancies but no one re-attended on subsequent pregnancies. The women did not recall any education about pelvic floor exercises: "I don't recall them actually going through it" (P3), and they were told that "it was 
just that your pelvic floors would be weak after giving birth" (P4). The only time that PFMEs were discussed in the ante-natal period, was during the ante-natal classes, and even then, the exercises were not explained or practised, and there was a lack of clarity about the reasons for carrying out the exercises: "They talked about an elevator going up and down.... I didn't really take it in" (P2).

The women were reminded of the PFMEs either verbally ("my first memory...... I was leaving the hospital and the midwife said, 'make sure and do your pelvic floor exercises'." (P6)), or in a leaflet, which most participants considered was not an effective method of educating mothers, and did not help the women adhere to carrying out PFMEs.

"I would have been given a leaflet but I probably just put it away and not really concerned myself with it" (P1)

There was one woman who did find the leaflet useful because of the nature of the information included in it.

"I got a leaflet....it was a very specific timeline, very specific amount to do, how many times to do it, and I got stuck in straight away then and I brought it home and did it at home religiously" (P4)

When asked whether they felt that they were treated differently on their first pregnancy compared to subsequent pregnancies from a PFME perspective, there was a mixed response with some women believing that they were better educated and given more information on subsequent pregnancies, and others who thought that there was no difference between information received during the first or subsequent pregnancies. Women were reminded about the PFMEs: "it was just always that reminder to do them and a tick box exercise, but nobody really put any emphasis on it from pregnancy one to pregnancy four" (P6), but it was very clear from all interviewees that they felt that there was insufficient detail regarding how to perform PFMEs, and the importance of carrying out the exercises was not emphasised enough, as illustrated below, by two of the women. 
"the midwife mentioned it briefly, but again it was just general chit chat, or it was mentioned at appointments, but it was brushed over, there was no real importance put on it" (P6)

"I think if I had been more aware... I didn't see the physio after my first baby at all.

Pelvic floor? it was very much left to your own devices." (P4)

Informal

All six interviewees felt that they were more aware of incontinence and the term "pelvic floor exercises" on second or subsequent pregnancies. This was not because of better education from health professionals, who could be considered experts, and who have had formal training, but rather from informal sources such as family, friends and media.

"I was definitely more aware from talking to my friends and from googling that the connection was there between the two things [PFME and leaking] on my second [child], but certainly not from a midwife point of view or a doctor point of view..." (P4)

Women did not feel that they understood how to do PFME any better but they knew that they should be doing them. The exact technique was still unclear for all the women but it was apparent from informal sources that it was something that should be done to help with "leaking". All women were aware of the possibility of "leaking" during or after subsequent pregnancies, and five women still believed leaking was "normal" because of the informal education they received.

"I remember after having my second [child] a friend came in and she was laughing, and she said to me 'oh you'll never laugh the same again!'. I said, 'what you mean?' and she said, 'you'll always leak!......oh yeah, never the same!' "(P5)

\section{Discussion}

The aim of this study was to investigate women's experiences of PFME prescription in relation to their ante- and post-natal care. We were particularly interested in whether women were prescribed 
PFME on their second and subsequent pregnancies, due to the association between incontinence and parity.

PFMEs have been shown to significantly reduce UI in the short term [23,25,28,43]. Elliot et al [44] have also shown positive long-term results for $50 \%$ of participants who remained continent after 7 years, however, high adherence to PFME training protocols was required to achieve positive effects. None of the participants in this study followed a training protocol or systematically performed an ante-natal programme as recommended by Miquelutti et al [29] to reduce complaints of UI. In fact, half of the participants were not taught how to perform PFMEs in their ante natal programmes at all and some were not sure if they were using the right technique. None of the women in this study felt that they understood the reason for PFMEs. They did not recall being told of any link between PFME and incontinence, therefore, women did not understand the reason for doing the exercises, and did not attach any importance to PFMEs. Interestingly, the women felt that if they had understood the importance of the pelvic floor muscles in relation to incontinence then they would have been more compliant with their exercises.

As well as the lack of effective teaching in the antenatal period, there was criticism for the way PFME were discussed and taught in the post-natal period. For example, only one woman received a visit from a physiotherapist whilst on the post-natal ward and this was on her $3^{\text {rd }}$ pregnancy. Even though she was told to do PFME she still did not understand that it had any relationship to incontinence. Five out of six women interviewed for this study reported that they thought urinary incontinence was a "normal" occurrence post-partum. This is consistent with previous studies in which women saw incontinence as an inevitable consequence of childbirth and therefore regarded it with less concern $[11,32,45]$. This form of passive acceptance appeared to lessen the distress and has also been cited in previous studies as an explanation for women not seeking treatment $[32,46,47]$. Whitford and Jones [48], when looking at pregnant women's motivation to perform PFME, found that women valued other people's opinions, even if it was only of personal relevance. In this study, 
all the women who felt incontinence was normal, reported that they had friends or relatives who also thought incontinence was normal, or that there was no effective treatment for it.

Our study supports findings by Whitford and Jones [48] who reported that low intention to do PFME was associated with a low belief in the likelihood of incontinence. In this study the low belief was due to a lack of education and understanding. Furthermore, the women in this study believed that there could be better outcomes if there was improved adherence to PFMEs, and that it is essential that the woman has confidence in her ability to carry out the exercises correctly. Thus it is vital that healthcare professionals, such as physiotherapists and midwives, highlight the importance of PFMEs as a way to reduce the risk of incontinence, ensure that the exercises are carried out correctly, and that the woman feels competent in managing these. The women in our study were not confident that they were performing the PFMEs correctly, and this, coupled with the lack of understanding of the link between PFMEs and UI, resulted in a lack of adherence to a PFME program.

The main method of teaching PFME post-natally was in the form of a leaflet left by the bedside, and most women did not place any importance on it when they were being given so much other information about feeding and caring for their baby. This practice does not follow recommendations of best practice from previous studies. PFMEs are more effective during pregnancy and after child birth if a special training programme, including help to identify the pelvic floor muscles, is used compared to written instructions left at the bedside $[25,30]$. When taught under the direction of a therapist, UI has been reduced in the short term compared with simple advice about PFME [20]. Detailed instruction on how to perform PFME, usually comprising of one or more practice sessions with a physiotherapist, have also been suggested [49]. It appears that this care was not provided for the women in this study. A test to ensure each participant can perform an effective pelvic floor muscle contraction is also recommended. Whether this was an internal examination or observational would depend on timing and patient consent, and is outside the remit of this study. 
An unexpected finding of this study was that every participant received most of their education about incontinence from informal sources such as family, friends, media or the internet. This was more prevalent on subsequent pregnancies and it was from these sources that all women became aware of incontinence in relation to PFME. Unsurprisingly the information was not always accurate, therefore women did not always find the appropriate form of treatment. In fact, most women felt that there was no treatment available for such symptoms. This finding confirms that there is a gap in education being provided by health professionals and this gap is being filled by informal and often inaccurate sources. It seems to be the case that there are discrepancies between what health professionals think they are teaching women, and the information that women are recalling. Women's awareness of incontinence and of the term PFME was heightened in subsequent pregnancies, compared to first pregnancy, but this was not due to education provided by health professionals, rather, the awareness was from the media or informal conversations, usually in a jokey context that the women would have had with friends or relatives.

The hypothesis of this study was that first-time mothers were better educated regarding PFME than women on subsequent pregnancies. We based this on the high numbers of women who attend antenatal classes during their first pregnancy where it is possible that these first time mothers will be encouraged to engage in PFME and therefore increase the likelihood of their continuing the exercise regime in future pregnancies [50]. This hypothesis was not correct. Our study found that the PFME training was inadequate for first and subsequent pregnancies. Women were given a leaflet about PFMEs, and although PFMEs were mentioned either ante-natally or post-partum in most cases, women did not link these exercises to UI. All the women agreed that the education they received from health professionals was not enough to ensure they adhered to the exercise program, and therefore help prevent incontinence. They did not feel that their education of PFME, in the health care setting, was sufficient either on first or subsequent pregnancies. They did feel better educated, however inaccurately it may have been, on subsequent pregnancies from informal sources. None of the women were aware that PFME should be continued long term and that incontinence symptoms 
could start any time and not just immediately post-partum. This supports findings elsewhere regarding the long-term lack of adherence where women were followed up at 15 years [34].

NICE guidelines (2017) recommend that from 10 week's gestation, that women are given information about exercise, including pelvic floor exercises [51], however, there is little further detail, and the focus is on other health and well-being issues for the pregnant woman and her baby. In Ireland, the HSE has issued a number of guidelines in relation to managing the care of a pregnant woman, but these do not include the prevention or management of incontinence. Likewise, the Royal College of Obstetricians and Gynaecologists (RCOG), based in the UK, also provides information for clinicians, however we did not find guidance for the prevention or management of incontinence here, either. There are guidelines and advice $[52,53]$ on the management of incontinence, but these are not linked to the guidelines regarding pregnant women. It would seem, therefore, that although healthcare professionals who manage people with incontinence, are aware of the link between pregnancy and incontinence, the healthcare professionals who manage pregnant women do not include clear guidelines on preventing and managing incontinence in this population, in either the short- or long-term care pathway.

Although the HSE in Ireland does not have a specific guideline regarding managing $\mathrm{UI}$ in pregnant women, there is strong evidence for the prescription of PFMEs to reduce incontinence. Healthcare professionals in Ireland, therefore, can be encouraged to follow this evidence and include the prescription of PFMEs in their practice. Within the HSE provision for pregnant women, there are many opportunities to encourage PFMEs: during routine ante-natal care, during ante-natal classes (primarily for primigravida women), immediately post-natally and during routine follow-up care. In general, the focus of care seems to be on the health and welfare of the baby as well as the general health of the mother, both of whom currently receive good medical and nursing care. Our study suggests that there is little emphasis on the specific 
issue of incontinence, and the need for women, especially multi-parous women, to carry out effective PFMEs over a long-term period in order to reduce the risk of UI.

\section{Limitations}

There are some limitations to this study. We reached data saturation because we had a focussed research question. This focus was, in itself, a limitation, but was necessary as we were working within tight time constraints. We would have liked to have further explored some other aspects of this topic such as the informal education of women by their family, friends and the media, and are therefore planning further work in this area.

This study focussed on women with incontinence. It is possible that the experiences of asymptomatic women may have been different, however, the experiences and opinions of women with incontinence will provide more insight into how to improve the services as they are the population who are requiring treatment.

The participants in this study came from one geographical area in Ireland. It is possible that there are different practices regarding the prescription of PFMEs in other parts of Ireland, and so our results are not necessarily transferable across the country. Further research should investigate the prescription of PFMEs, nationally.

\section{Conclusion}

Women did not feel that they were properly educated by health professionals on either their first or subsequent pregnancies. Whether this is due to poor education from health professionals or issues with how the information is understood and adhered to by the women, is beyond the remit of this study and needs to be further investigated.

Written information at the bedside seems to be the main source of information for women despite this being shown to be generally ineffective. When information is given in this way, our study 
suggests that it should give very specific and clear information regarding PFMEs, how to check that they are being performed effectively, and how to progress the dose of exercise as the muscles strengthen. It would be better to include an additional mode of education, as per best practice recommendations, such as assessment and, where necessary, treatment by a physiotherapist $[19,49]$.

We recommend that within the healthcare system, that a greater focus is placed on education re PFMEs and their role in the prevention of incontinence, especially when managing the health of pregnant women who are one of the groups at risk of developing this problem, i.e. during the routine ante- and post-natal healthcare provision. We suggest that incontinence is managed much earlier, i.e. at a time of potential risk (such as pregnancy), rather than much later, when symptoms have negatively affected QoL and well-being. Finally, we would encourage that national guidelines regarding the management and care of pregnant women, should specifically include guidance for the prevention of incontinence in this population. 


\section{References}

1. Sansawang B, Sansawang N. Stress urinary incontinence in pregnant women: A review of prevalence, pathophysiology and treatment. Int Urogynecol J. 2013;24:901-912

2. MacArthur C, Wilson D, Herbison P, Lancashire RJ, Hagen S, Toozs-Hobson P, Dean N, Glazener C, on behalf of the Prolong study group. Urinary incontinence persisting after childbirth: extent, delivery history, and effects in a 12-year longitudinal cohort study. BJOG $2016 ; 123: 1022-1029$

3. Abrams P, Andersson KE, Brubaker L, Cardozo L, Cottenden A, Denis L, et al. 3RD International Consultation on Incontinence. Recommendations Committee: Evaluation and Treatment of Urinary Incontinence, Pelvic organ prolapse and Fecal Incontinence. 2005

4. Hunskaar S, Burgio K, Diokono A, Herzog AR, Hjalmas K, Lapitan MC. Epidemiology and natural history of urinary incontinence in women. Urology. 2003;62(4):16-23

5. Wesnes SL, Rortveir G, Bo K, Hunskaar S. Urinary Incontinence during pregnancy. Obstet Gynecol.2007;109(4):922-928

6. Temml C, Haidinger G, Schmidbauer J, et al. Urinary Incontinence in both sexes: prevalence rates and impact on quality of life and sexual life. Neurourol Urodyn. 2000;19:259-271

7. Mascarrenhas T, Coelho R, Oliveira M, Patricio, B. Impact of urinary incontinence on quality of life during pregnancy and after child birth. Paper presented at the 33rd annual meeting of the International Continence Society. 2003

8. Chiarelli P, Brown WJ. Leaking urine in Australian women: prevalence and associated conditions. Women Health.1999;29:1-13

9. Hojberg KE, Salvig JD, Winslow NA, Lose G, Secher NJ. Urinary incontinence: prevalence and risk factors at 16 weeks gestation. Br J Obstet Gynaecol.1999;106:842-50

10. Kristiansson, P, Samuelsson E, Von Schoultz B, Svardsudd K. Reproductive hormones and stress urinary incontinence in pregnancy. Acta Obstet Gynecol Scand. 2001;80:1125 - 30 
11. Hemachandra NN, Rajapaksa LC, Maderson L. A "usual occurrence:" Stress incontinence among reproductive aged women in Sri Lanka. Social Science and Medicine. 2009; 69:1395-1401

12. Perera J, Kirthinanda DS, Wijeratne S, Wickramarachchi TK. Descriptive cross-sectional study on prevalence, perceptions, predisposing factors and health seeking behaviour of women with stress urinary incontinence. BMC Women's Health. 2014; 14:78

13. Ruiz de Viñaspre Hernández R, Tomás Aznar C, Rubio Aranda E. Factors associated with treatment-seeking behaviour for postpartum urinary incontinence. Journal of Nursing Scholarship. 2014; 46:6:391-397

14. Őzdemir OC, Bakar Y, Őzengin N, Duran B. The effect of parity on pelvic floor muscle strength and quality of life in women with urinary incontinence: a cross-sectional study. J Phys Ther Sci. 2015; 27:2133-2137

15. Townsend MK, Lajous M, Hernán Medina-Campos R, Catzin-Kuhlmann A, López-Ridaura R, Rice MS. Int Urogynecol J. 2017; 28:769-776

16. Zhou H-H, Shu B, Liu T-Z, Wang X-H, Yang Z-H, Guo Y-L. Association between parity and the risk for urinary incontinence in women. A meta-analysis of case-control and cohort studies. Medicine. 2018; 97:28(e11443)

17. Wilson PD, Berghmans B, Hagen S et al. Adult Conservative Management. In: Abrams P, Cardozo L, Khoury S, Wein A. Third international consultation on incontinence. Monaco: Health Publications. 2004

18. Marques A, Stother L, Macnab A. The status of pelvic floor muscle training for women. CUAJ. 2010;4(6):419-424

19. Fritel X, Fauconnier A, Bader G, Cosson M, Debodinance P, Deffieux X. Diagnosis and management of adult female stress urinary incontinence: guidelines for clinical practice from the French College of Gynaecologists and Obstetricians. Euro J Obstet Gynecol Reprod Biol. 2010;151(1):14-19 
20. Wilson PD, Herbision RM, Herbison GP. Obstetric practise and the prevalence of urinary incontinence three months after delivery. Br J Obstet Gynaecol. 1996;103:154-61

21. Sampselle CM, Miller JM, Mims BL, Delancy JOL, Ashon-Miller JJ, Antonakos CL. Effect of pelvic muscle exercise on transient incontinence during pregnancy and after child birth. Obstet Gynecol. 1998;91:406-12

22. Hay-Smith J, Morkved S, Fairbrother KA and Herbison GP. Pelvic floor muscle training for prevention and treatment of urinary and faecal incontinence in ante and post-natal women. Cochrane database systematic reviews. 2008;4:CD007471

23. Morkved S, Bo K. Effect of post-partum pelvic floor muscle training in prevention and treatment of urinary incontinence: a 1 year follow up. BJOG. 2000;107:1022-1028

24. Boyle R, Hay-Smith JC, Cody JD, Morkved S. Pelvic floor muscle training for prevention and treatment of urinary and faecal incontinence in antenatal and postnatal women. Cochrane Database of Systematic Reviews. 2012. Available from: http://onlinelibrary.wiley.com/doi/10.1002/14651858.CD007471.pub2

25. Glazener CM, Herbison GP, Wilson PD, MacArthur C, Lang GD, Gee $\mathrm{H}$ et al. Conservative management of persistent postnatal urinary and faecal incontinence: a randomised controlled trial. BMJ.2001;323:1-5

26. Viktrup L, Lose G. Lower urinary tract symptoms 5 years after the first delivery. Int Urogynecol J Pelvic Floor Dysfucntion. 2000;11:336-340

27. Morkved S, Bo K, Schei B, Salvesen KA. Pelvic floor muscle training during pregnancy to prevent urinary incontinence: a single blind randomized controlled trial. Obstet Gynecol. 2003;101(2):313-319

28. Dumoulin C, Lemeiux MC, Bourbonnaise D et al. Physiotherapy for persistent post-natal stress urinary incontinence: A randomized controlled trial. Obstet Gynaecol. 2004; 104(3):504-510 
29. Miquelutti MA, Cecatti JG, Makuch, MY. Evaluation of a birth preparation programme on lumbopelvic pain, urinary incontinence, anxiety and exercise: a randomized controlled trial. Pregnancy and Childbirth. 2013;13:154

30. Morkved S, Bo K. The effect of post-partum pelvic floor muscle exercise in the prevention and treatment of urinary incontinence. Int Urogynecol J Pelvic Floor Dysfunct. 1997; 8:21722

31. Mason L, Glenn S. Walton I, Hughes C. The instruction in pelvic floor exercises provided to women during pregnancy or following delivery. Midwifery. 2001a;17(1):55-64

32. Mason L, Glenn S, Walton I, Hughes C. Women's reluctance to seek help for stress incontinence during pregnancy and following childbirth. Midwifery. 2001b;17(3):212-221

33. Goode PS, Burgio KL, Locher JL et al. Effect of behavioural training with or without pelvic floor electrical stimulation on stress incontinence in women: a randomized control trial. JAMA. 2003;290(3):345-352

34. Bo K, Kvarstein B, Nygaard I. Lower urinary tract symptoms and pelvic floor muscle exercise adherence after 15 years. Obstet Gynecol. 2005;105:999-1005

35. Ashworth PD, Hagan MT. The meaning of incontinence: a qualitative study of nongeriatric urinary incontinence sufferers. Journal of Advanced Nursing. 1993; 18:14151423

36. Zeznock DE, Gilge FL, Bradway C. Living with Urinary Incontinence: Experiences of women from 'The Last Frontier'. Urologic Nursing. 2009; 29(3):157-185

37. Hayder D, Schnepp W. Experiencing and managing urinary incontinence: a qualitative study. Western Journal of Nursing Research. 2010; 32(4):480-496

38. Hamid TA, Pakgohar M, Ibrahim R, Dastjerdi MV. 'Stain in Life': The meaning of urinary incontinence in the context of Muslim postmenopausal women through hermeneutic phenomenology. Archives of Gerontology and Geriatrics. 2015;60(3):514-21 
39. Melville J. Women's perceptions about the etiology of urinary incontinence. Journal of Women's Health. 2008; 17(7):1093-1098

40. Parahoo K. Nursing Research. Principles, Process and Issues. Macmillan. 1997

41. Polit DF, Beck CT. Essentials of Nursing Research: Appraising Evidence for Nursing Practice.7th edn. Philadelphia, Wolters Kluwer Health | Lippincott Williams \& Wilkins. 2010

42. Saldaña J. The Coding Manual for Qualitative Researchers, $3^{\text {rd }}$ Edition. Sage Publications 2016

43. Kim EY, Kim SY, Oh DW. Pelvic floor muscle exercises utilising trunk stabilisation for treating post-partum urinary incontinence: randomized controlled pilot trial of supervised versus unsupervised training. Clin Rehabil. 2012; 26(2):132-141

44. Elliott V, Dumoulin C, Martin C et al. Physiotherapy for persistent post-partum stress urinary incontinence: A seven year follow up study. Neurourol Urodyn. 2009;28(7):820

45. Marecki M, Seo JY. Perinatal urinary and fecal incontinence: suffering in silence. Perinat Neonatal Nurs. 2010;24(4):330-40

46. Goldstein M, Hawthorn ME, Enberg S et al. Urinary Incontinence: Why people do not seek help. J Gerontolog Nurs. 1992;18(4):15-20

47. Da Silva L, De Moraes Lopes MH. Urinary Incontinence in Women: Reasons for not seeking treatment. Rev Esc Enferm USP. 2009;43(1):68-74

48. Whitford HM, Jones M. An exploration of the motivation of pregnant women to perform pelvic floor exercises using the revised theory of planned behaviour. $\mathrm{Br} \mathrm{J}$ Health Psych. 2011;6:761-778

49. Lagro-Janssen ALM, Debruyne FMJ, Smits AJA et al. Controlled trial of pelvic floor exercises in the treatment of urinary stress incontinence in general practice. 1991; 41:445-449

50. Palmer C, Burwitz L, Smith N, Borrie A. Enhancing fitness training adherence of elite netball players: An evaluation of Maddux's revised theory of planned behaviour. J Sports Sciences. 2000; 18:627-641 
51. National Institute for Health and Care Excellence (NICE) 2008 (updated 2017) Antenatal care for uncomplicated pregnancies. Clinical Guideline 62. Available: nice.org.uk/guidance/cg62

52. National Institute for Health and Care Excellence (NICE) 2013 (updated 2015) Urinary incontinence in women: management. Clinical Guideline 171. Available: nice.org.uk/guidance/cg171

53. Health Service Executive. Continence Promotion. Available: https://www.hse.ie/eng/services/list/4/olderpeople/tipsforhealthyliving/continencepromoti on.html\#Managing\%20incontinence 
Appendix 1 - Figure 1: Themes

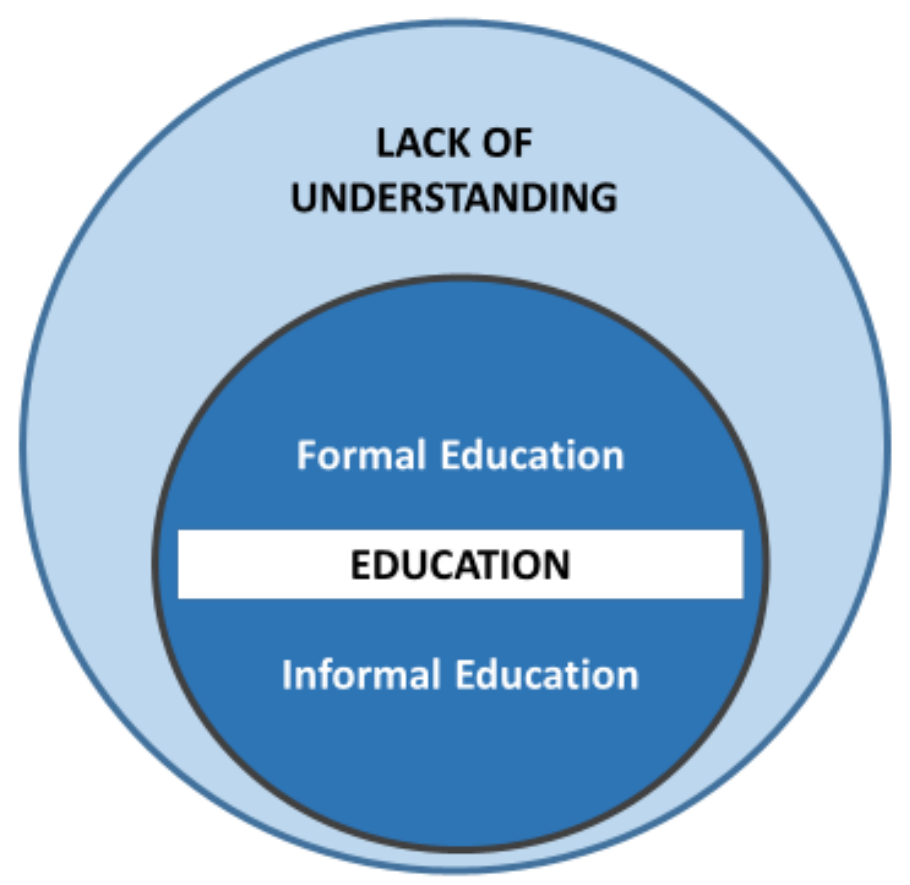

